\title{
Inclusão Digital em Escolas e Comunidades Indígenas
}

\author{
Fernando Selleri, Elias Januário, Graziella S. Silva, Caroline Q. de Oliveira, \\ Everton R. do Nascimento, Ivanildo M. Azevedo \\ Grupo de Pesquisa Mosaico Intercultural - Universidade do Estado de Mato Grosso \\ Caixa Postal 92 - 78.390-000 - Barra do Bugres - MT - Brasil \\ \{selleri.br, mosaico.unemat, everton.nascimento, vando.aze\}@gmail.com, \\ eliasjanuario@terra.com.br
}

\begin{abstract}
This work investigates the availability and use of information technology (IT) in indigenous schools and communities of Mato Grosso. Data came from literature and documents, as well as visit to five Indigenous Lands, with observations and interviews. The results indicate the need for training and support materials for IT use in school activities and challenges related to infrastructure improvement.
\end{abstract}

Resumo. Neste trabalho são investigadas a disponibilidade e a utilização de recursos de tecnologia da informação (TI) nas escolas e comunidades indígenas de Mato Grosso, considerando a importância da inclusão digital dos povos indígenas. Os dados foram obtidos por meio de pesquisa bibliográfica e documental, além de visita a cinco Terras Indígenas, realizando observações e entrevistas. Os resultados apontam a necessidade da oferta de treinamentos e materiais de apoio ao uso de TI nas atividades escolares e os desafios relacionados à melhoria da infraestrutura.

\section{Introdução}

As discussões em torno da inclusão digital têm ganhado evidência nos últimos anos, motivadas, entre outros aspectos, pelo aumento na oferta de serviços e soluções que utilizam recursos de Tecnologia da Informação (TI) como mediadores, principalmente nos serviços ao cidadão, cada vez mais disponibilizados via internet. Neste cenário, é importante que se discuta a inclusão digital em comunidades e escolas indígenas.

O presente trabalho tem como objetivo investigar a disponibilidade de recursos de TI e o cenário de inclusão digital nas Terras Indígenas em Mato Grosso, com o propósito de diagnosticar como os recursos de TI são utilizados no contexto da escola e da comunidade e quais ações podem ser realizadas para melhorar essa utilização. A pesquisa aponta possibilidades de contribuir com as políticas públicas desenvolvidas para os povos indígenas do estado, no que se refere a inclusão digital indígena.

A partir desta introdução, a Seção 2 aborda a metodologia de pesquisa. A Seção 3 discute os resultados obtidos. E as considerações finais são apresentadas na Seção 4.

\section{Metodologia}

Inicialmente, a metodologia de pesquisa adotada para este trabalho teve foco na Pesquisa Bibliográfica e Documental [Santos 2005], buscando identificar na literatura questões 
relacionadas ao uso de TI e à inclusão digital em Terras Indígenas. A pesquisa documental ocorreu no acervo de instituições ligadas a questão indígena, em particular no Acervo Joana Saira/UNEMAT.

Em um aspecto mais abrangente também foi adotado como método uma perspectiva etnográfica [Lüdke e André 1986]. Atentando-se à movimentação do cotidiano, a equipe visitou cinco Terras Indígenas em setembro de 2012, coletando dados sobre a utilização dos recursos de TI nas escolas e comunidade indígenas, envolvendo seis escolas, oito aldeias, três etnias e oito entrevistas. Os dados foram obtidos por meio de observações, entrevistas semiestruturadas, anotações em diários de campo e registro fotográfico. As reflexões foram constituídas a partir dos dados coletados. A pesquisa reuniu pesquisadores das áreas de Educação, Antropologia e TI.

\section{Resultados}

\subsection{A importância da TI}

Uma questão inicial que motivou a pesquisa foi identificar a importância que a TI possui para as comunidades indígenas. Os aspectos identificados durante as visitas às Terras Indígenas foram: realização de trabalhos; utilização em aula, tornando-as mais dinâmicas; contato com outras comunidades, aldeias e instituições; romper distâncias, para obter informação de forma mais rápida; facilitar a comunicação e o planejamento pedagógico; valorizar e registrar a cultura; divulgação de materiais. Estes aspectos se assemelham aos descritos em um relatório da área de Informática I [Selleri, Moraes e Buzatto 2011], envolvendo 50 professores indígenas, de 27 etnias e 28 Terras Indígenas, dos Cursos de Licenciatura Intercultural da UNEMAT.

\subsection{Recursos de TI disponíveis}

A pesquisa também buscou identificar recursos de TI disponíveis nas aldeias. Em um relatório da área de Informática II [Selleri e Almeida 2012], 40 professores indígenas, de 25 etnias e 23 Terras Indígenas, listaram de forma espontânea os recursos tecnológicos existentes em suas aldeias. Os mais listados foram: televisão, por 37 professores (92,5\%); computador, por 33 professores $(82,5 \%)$; notebook, por 26 professores $(65 \%)$; aparelho celular, por 23 professores $(57,5 \%)$; e internet, por 20 professores $(50 \%)$. Outros itens foram lembrados, como DVD player, antena parabólica, telefone público, aparelho de som, impressora, câmera fotográfica, câmera filmadora, projetor multimídia, gravador e pen drive. As visitas identificaram, além dos recursos já citados, rádio, smartphone, sinal de celular, TV por assinatura e tablet.

Contudo, diferentes realidades foram reveladas durante as visitas. Por exemplo, a Escola Municipal Zozoiterô / Escola Estadual Malamalali (Figura 1) - Terra Indígena Paresi, aldeia Rio Verde, etnia Paresi, Tangará da Serra - contava com laboratório de informática oriundo do PROINFO [MEC 2013] e de doações da associação indígena local. A Escola Municipal Wazare (Figura 2) - Terra Indígena Utiariti, aldeia Wazare, etnia Paresi, Campo Novo do Parecis - não contava sequer com energia elétrica, nem laboratório de informática. A Escola Municipal Cravari (Figura 3) - Terra Indígena Manoki, aldeia Cravari, etnia Irantxe, Brasnorte - eventualmente usava equipamentos de um Ponto de Cultura [MINC 2013], não dispondo de equipamentos próprios. Os equipamentos encontrados na comunidade, em sua maioria, eram de aquisição própria. 


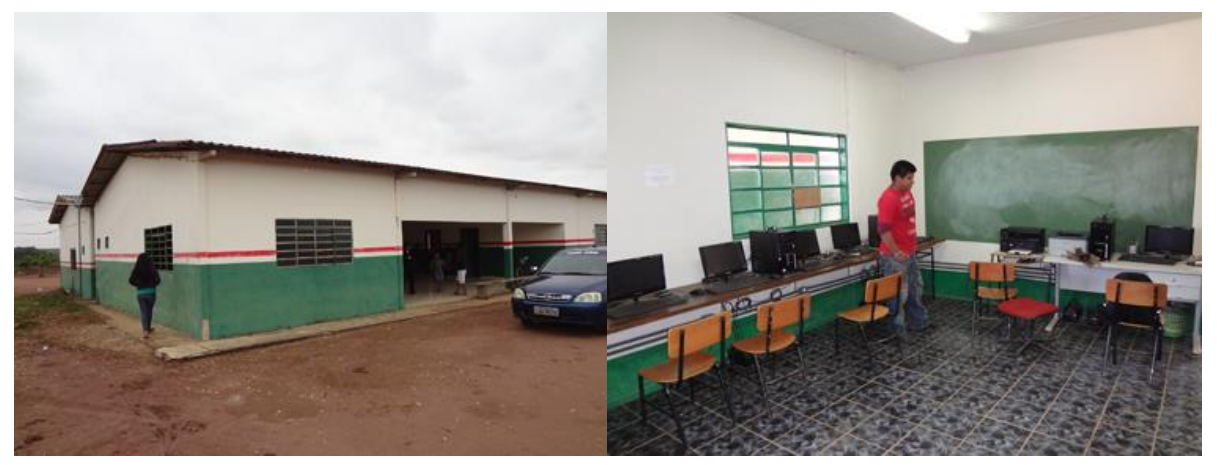

Figura 1. Escola Zozoiterô/Malamalali e Laboratório de Informática (Foto: Acervo Projeto Inclusão Digital)

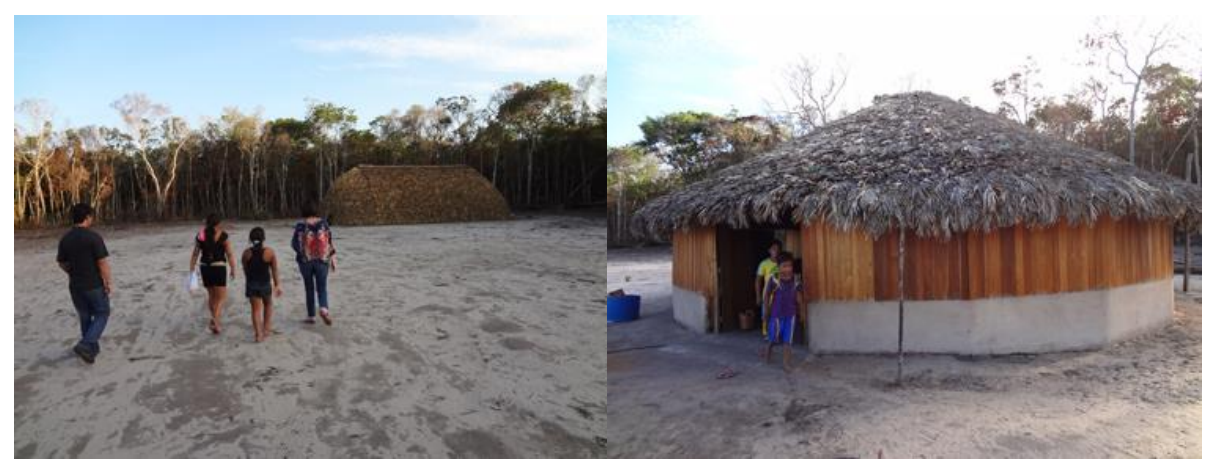

Figura 2. Aldeia e Escola Wazare (Foto: Acervo Projeto Inclusão Digital)

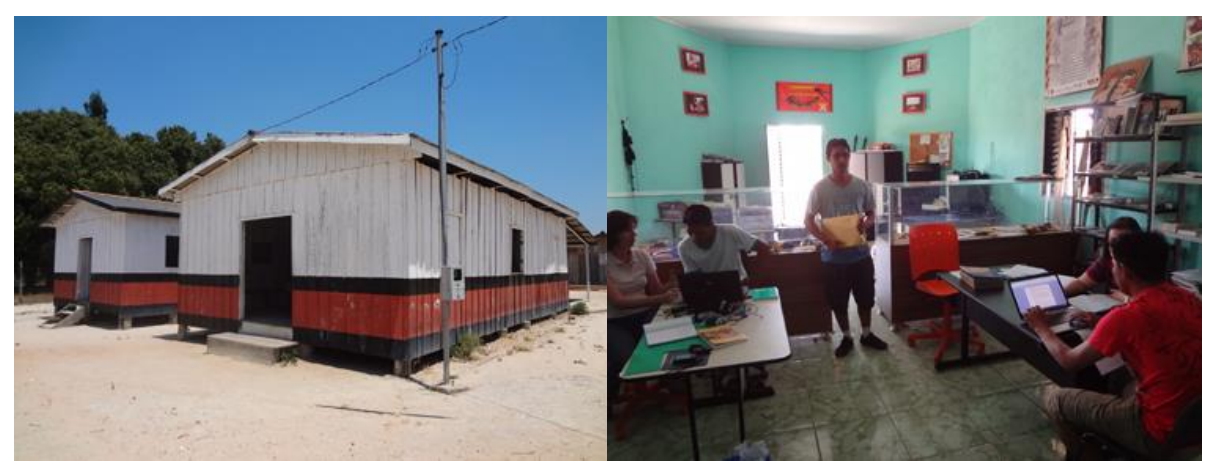

Figura 3. Escola Cravari e Instalações do Ponto de Cultura (Foto: Acervo Projeto Inclusão Digital)

\subsection{Uso dos recursos de TI}

Os recursos de TI, quando disponíveis, geralmente são utilizados para trabalho, muitos associados às atividades escolares, e para entretenimento, como ressaltado nas falas de professores entrevistados, transcritas a seguir.

"Comunicação com outras pessoas, entretenimento e informação." (Entrevistado 1, Etnia Paresi)

"A televisão, usamos para entretenimento. O notebook, para facilitar atividades da escola." (Entrevistado 2, Etnia Paresi)

"A internet é usada para fazer projetos. A TV para divertimento" (Entrevistado 4, Etnia Nambikwara) 
Os laboratórios de informática nas escolas são utilizados geralmente para atividades relacionadas ao aprendizado de informática básica. O uso como suporte às aulas das disciplinas ou componentes curriculares (ex. Matemática, Línguas e outras) se dá por meio da elaboração de trabalhos, pesquisas, entre outros.

"O laboratório é usado para cursos de informática e algumas iniciativas para uso em aula." (Entrevistado 2, Etnia Paresi)

"Usamos para elaboração de projetos e trabalhos culturais." (Entrevistado 7, Etnia Irantxe)

Às vezes o computador ou o notebook é levado à sala de aula pelo professor. Um dos entrevistados destacou que a utilização de recursos de TI também parte de iniciativas dos próprios alunos.

"O notebook é usado para as crianças assistirem vídeo" (Entrevistado 5, Etnia Paresi)

"Os alunos com notebooks pesquisam sobre temáticas de trabalhos na internet." (Entrevistado 8, Etnia Irantxe)

Embora os recursos de informática tenham sido citados como ferramentas para auxiliar no trabalho, eles também são utilizados para entretenimento na comunidade.

"O notebook eu uso para digitar provas, fazer materiais para a escola e assistir vídeos, entretenimento.” (Entrevistado 5, Etnia Paresi)

"Os computadores também são usados para assistir vídeos, ouvir música no final de semana, fazer trabalhos e para jogar." (Entrevistado 6, Etnia Irantxe)

Recursos como câmeras são utilizados nas ações escolares, para registro de atividades culturais, como destaca o depoimento seguinte.

"Usamos para o registro da cultura por meio de vídeo e exibição do vídeo na escola." (Entrevistado 8, Etnia Irantxe)

$\mathrm{Na}$ escola, a televisão é utilizada para exibição de vídeos aos alunos, sobre cultura e outros temas. Em casa, a televisão é assistida por adultos e por crianças.

"A TV é para assistir jogos, novelas e desenhos, para as crianças." (Entrevistado 3, Etnia Paresi)

\subsection{Desafios e possibilidades}

Quando questionados sobre ações que podem ser desenvolvidas para promover a inclusão digital nas comunidades indígenas, a Internet foi destacada como o principal recurso a ser disponibilizado, seguido por laboratório de informática e oferta de cursos. A energia elétrica também foi citada. Os relatos a seguir destacam a questão da disponibilidade de infraestrutura e oferta de cursos.

“Infraestrutura para implantar laboratório." (Entrevistado 8, Etnia Irantxe)

"Cursos para contribuir com a escola e a comunidade para facilitar o uso da tecnologia." (Entrevistado 2, Etnia Paresi) 
Notou-se também, durante o trabalho de coleta de dados, uma demanda pela disponibilidade de materiais, tais como softwares, vídeos, tutoriais, entre outros, que deem apoio ao uso do recursos de TI durante as aulas de componentes curriculares nas escolas indígenas. Alguns relatos destacaram a preocupação existente em torno da TI.

"A comunidade se preocupa com o lado negativo, deve saber utilizar." (Entrevistado 2, Etnia Paresi)

As visitas reforçaram alguns desafios, apontados em Selleri et al. (2010), como a manutenção dos equipamentos nas comunidades indígenas e o deslocamento de instrutores até as mesmas, em virtude da distância dos centros urbanos.

\section{Considerações}

O presente trabalho representa uma discussão inicial sobre a utilização de recursos de TI nas comunidades indígenas em Mato Grosso, na qual foi possível identificar aspectos que motivam a busca por recursos de TI, recursos disponíveis nas escolas e comunidades indígenas e sua utilização, além de desafios relacionados a inclusão digital nas Terras Indígenas. Com relação às limitações do trabalho, a principal consiste no pequeno número de Terras Indígenas visitadas, compreendendo basicamente povos que habitam a região do cerrado mato-grossense.

Trabalhos futuros incluem visitas em outras Terras Indígenas, de diferentes regiões, para novas coletas de dados. Sugere-se também a elaboração de propostas que atendam as demandas relacionadas a infraestrutura e treinamento, identificadas nas comunidades já pesquisadas. Um estudo mais aprofundado acerca dos impactos que a TI tem causado nas comunidades indígenas também é recomendado.

\section{Referências}

Lüdke, M. e André, M. E. D. (1986), Pesquisa em Educação: Abordagens Qualitativas, São Paulo, EPU.

MEC, Ministério da Educação (2013) "Programa Nacional de Tecnologia Educacional PROINFO”, http://gestao2010.mec.gov.br/o_que_foi_feito/program_87.php, Julho.

MINC, Ministério da Cultura (2013) "Ponto de Cultura", http://www2.cultura.gov.br/culturaviva/ponto-de-cultura/, Setembro.

Santos, I. E. (2005), Manual de Métodos e Técnicas de Pesquisa Científica, Niterói/RJ, Impetus, 5 ed.

Selleri, F. e Almeida, L. F. (2012), Relatório de Ciências da Natureza e Matemática II Informática, Barra do Bugres/MT, Acervo Joana Saira/UNEMAT.

Selleri, F., Moraes, K. P. C. e Buzatto, W. L. (2011), Relatório de Ciências Matemáticas e da Natureza I - Informática, Barra do Bugres/MT, Acervo Joana Saira/UNEMAT.

Selleri, F., Nascimento, E. R., Januário, E., Gutierres, S. R. e Cagnoni, R. (2010). Informática para Professores Indígenas: Elaboração de Publicações nas Escolas das Comunidades. In Anais do $16^{\circ}$ Workshop de Informática na Escola (WIE), Belo Horizonte, SBC.

Apoio: FAPEMAT Edital Universal no. 009-2011, Processo nº.729013/2011. 